\title{
Axial lumbar interbody fusion: a 6-year single-center experience
}

\author{
This article was published in the following Dove Press journal: \\ Clinical Interventions in Aging \\ 10 August 2013 \\ Number of times this article has been viewed
}

\section{Dick J Zeilstra' \\ Larry E Miller ${ }^{2,3}$ \\ Jon E Block ${ }^{3}$}

'Bergman Clinics, Naarden and NedSpine, Ede, The Netherlands;

${ }^{2}$ Miller Scientific Consulting, Inc, Arden, NC, USA; ${ }^{3}$ The Jon Block

Group, San Francisco, CA, USA
Correspondence: Jon E Block

The Jon Block Group, 2210 Jackson

Street, Suite 40I, San Francisco,

CA 94115 , USA

Tel +l 4157757947

Fax + I 4159280765

Email jonblock@jonblockgroup.com
Introduction: The aim of this study is to report our 6-year single-center experience with L5-S1 axial lumbar interbody fusion (AxiaLIF).

Methods: A total of 131 patients with symptomatic degenerative disc disease refractory to nonsurgical treatment were treated with AxiaLIF at L5-S1, and were followed for a minimum of 1 year (mean: 21 months). Main outcomes included back and leg pain severity, Oswestry Disability Index score, working status, analgesic medication use, patient satisfaction, and complications. Computed tomography was used to determine postoperative fusion status.

Results: No intraoperative complications, including vascular, neural, urologic, or bowel injuries, were reported. Back and leg pain severity decreased by $51 \%$ and $42 \%$, respectively, during the follow-up period (both $P<0.001$ ). Back function scores improved 50\% compared to baseline. Clinical success, defined as improvement $\geq 30 \%$, was $67 \%$ for back pain severity, $65 \%$ for leg pain severity, and $71 \%$ for back function. The employment rate increased from $47 \%$ before surgery to $64 \%$ at final follow-up $(P<0.001)$. Less than one in four patients regularly used analgesic medications postsurgery. Patient satisfaction with the AxiaLIF procedure was $83 \%$. The fusion rate was $87.8 \%$ at final follow-up. During follow-up, 17 (13.0\%) patients underwent 18 reoperations on the lumbar spine, including pedicle screw fixation $(n=10)$, total disc replacement of an uninvolved level $(n=3)$, facet screw fixation $(n=3)$, facet screw removal $(n=1)$, and interbody fusion at L4-L5 $(n=1)$. Eight $(6.1 \%)$ reoperations were at the index level.

Conclusion: Single-level AxiaLIF is a safe and effective means to achieve lumbosacral fusion in patients with symptomatic degenerative disc disease.

Keywords: AxiaLIF, interbody, fusion, lumbosacral, minimally invasive, presacral

\section{Introduction}

Degeneration of the lumbar intervertebral discs is common with advancing age, ${ }^{1,2}$ and it represents the primary cause of chronic low back pain in adults. ${ }^{3}$ Nonsurgical treatments such as physical therapy, analgesics, and activity modification are the first-line therapies for low back pain secondary to degenerative disc disease (DDD); however, patient prognosis with nonsurgical treatments is poor when symptoms persist for 6 months or more..$^{4-7}$ Lumbar interbody fusion is performed to improve lumbar stability and decrease painful motion at the offending motion segment when conservative treatments fail. Traditional surgical access corridors for interbody fusion include posterior, transforaminal, anterior, and extreme lateral - each of which is associated with a distinct risk profile that is largely related to iatrogenic injury of the anatomic structures that must be traversed to gain access to the index interspace. Minimally invasive spine surgery has been widely adopted since smaller access portals and less 
tissue disruption offer distinct patient advantages including less blood loss, shorter hospitalization, and fewer complications compared to open surgery. ${ }^{8}$ However, minimally invasive spine surgery is technically demanding and utilizes the same access points and trajectories as open surgery. Consequently, the same anatomic structures remain at risk, albeit lower, for iatrogenic injury. ${ }^{9}$

The presacral corridor is a largely aneural and avascular space beginning at the midline of S1-S2 and extending to the inferior endplate of S1, with a trajectory between the parietal fascia and the visceral fascia. Axial lumbar interbody fusion (AxiaLIF) is a minimally invasive technique that exploits this anatomic "safe zone" to achieve lumbosacral interbody access without the risk of jeopardizing critical neurovascular or musculoligamentous structures.

Studies with AxiaLIF have collectively reported clinically important reductions in pain and improvements in back function, with low complication rates. ${ }^{10-18}$ The largest study with AxiaLIF to date reported average improvements of $63 \%$ in back pain severity and $54 \%$ in back function with a $94 \%$ fusion rate and no major complications in 156 patients followed for 2 years. ${ }^{13}$ We performed a retrospective evaluation of patients treated with AxiaLIF at our institution over a 6-year period that had a minimum of 1-year clinical and radiographic outcome data.

\section{Methods}

\section{Patients}

A total of 131 patients with radiographically confirmed DDD who underwent L5-S1 interbody fusion via the axial presacral approach and had a minimum of 1 year follow-up were retrospectively included in this report. Surgeries were performed by a single surgeon at the Neurosurgical Centre in Zwolle or Bergman Clinics in Naarden and Nedspine in Ede, the Netherlands between March 2006 and January 2012. All patients underwent a minimum of 6 months (mean: 5 years) of unsuccessful nonsurgical management before the AxiaLIF procedure.

\section{Pretreatment evaluations}

Each patient underwent a complete physical and neurologic examination and completed a detailed medical and medication history. The diagnosis of DDD was confirmed with magnetic resonance imaging and $\mathrm{X}$-rays using anteroposterior and lateral views, as well as dynamic flexion-extension images. Additionally, provocative discography and subsequent anesthetization of the disc was routinely performed. Midsagittal T1- and T2-weighted magnetic resonance imaging of the sacrum and coccyx ruled out vascular anomalies, tumor, or surgical scarring that would preclude safe access through the presacral space. Patients with previous pelvic surgery were not considered for this procedure. No patient presented with spondylolisthesis, lumbar spinal stenosis, herniated nucleus pulposus, or failed back syndrome.

\section{AxiaLIF system}

Patients underwent L5-S1 interbody fusion with the AxiaLIF system via a minimally invasive presacral approach (Figure 1). The AxiaLIF system is indicated for patients requiring lumbar interbody fusion to treat DDD, pseudarthrosis, spinal stenosis, or spondylolisthesis (grade 1 or grade 2). Contraindications to this procedure include severe scoliosis, severe spondylolisthesis (grade 3 or grade 4), tumor, osteoporosis, or trauma. AxiaLIF received CE Mark clearance in March 2005.

\section{Surgical procedure}

Procedural steps have been discussed in detail elsewhere. ${ }^{19}$ Patients followed a bowel preparation protocol the night before surgery. At surgery, the patient was placed prone and, under fluoroscopic guidance, a $2 \mathrm{~cm}$ incision was made on either side of the paracoccygeal notch to gain entry to the presacral corridor. Blunt finger dissection was used to displace the rectum away from the sacrum and a blunt guide pin was then advanced through the presacral space and docked on the inferior endplate of the sacrum. A series of dilators were advanced over the guide pin and a working cannula was anchored with $\mathrm{K}$ wires to the sacrum. A cannulated drill created a bony channel in the sacrum and provided access to the L5-S1 disc. Nitinol cutters were used to morselize the disc material, completely preserving the annulus, and to denude

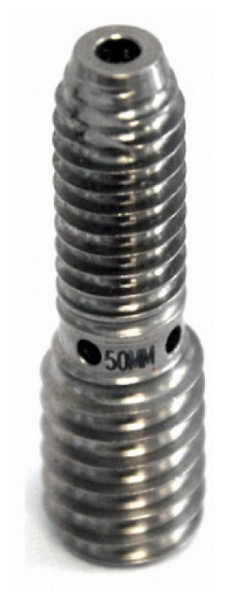

Figure I The AxiaLIF rod.

Note: $50 \mathrm{~mm}$ length shown.

Abbreviation: AxiaLIF, axial lumbar interbody fusion. 
and abrade the endplates to promote fusion. Bone graft substitute (Actifuse ${ }^{\mathrm{TM}}$ 75, Baxter International, Inc., Deerfield, IL, USA; Allomatrix ${ }^{\circledR} 26$, Wright Medical Technology, Inc, Arlington, TN, USA; DBX ${ }^{\circledR} 23$, Synthes, Inc., West Chester, PA, USA; Tutoplast ${ }^{\circledR}$ 4, Tutogen Medical, Inc, West Paterson, NJ, USA; NANOSTIM ${ }^{\text {Tм }}$ 3, Medtronic, Inc, Minneapolis, $\mathrm{MN}, \mathrm{USA}$ ) was inserted into the disc space. The guide pin was then advanced to the inferior L5 endplate and a twist drill was used to remove bone. The AxiaLIF rod was advanced through the sacrum and $0.5 \mathrm{~cm}$ to $1 \mathrm{~cm}$ into the $\mathrm{L} 5$ vertebral body. Advancement of the screw increases distraction across the disc space, leading to disc height restoration and opening of the L5-S1 neuroforamen (Figure 2). We began using percutaneous facet screw fixation with all AxiaLIF cases beginning in mid-2008. No other supplemental fixation devices were utilized in this series.

\section{Main outcomes and follow-up}

Clinical and radiographic outcomes were collected during regularly scheduled office visits at pretreatment, 6 weeks, and annually ( \pm 3 months) thereafter. All patients were followed at least through the 1-year follow-up visit (mean: $21 \pm 8$ months). Fusion mass was assessed by independent radiologists with thin-slice (1-2 mm), high-resolution computed tomography (CT) scan in coronal and sagittal planes at the 1-year follow-up visit. Fusion status was assessed on a 4-point grading scale; solid fusion was defined as radiographic evidence of bridging bone between L5 and S1. Back and leg pain severity were each assessed by the patient with a 0 to 100 numeric scale. Back function was evaluated with the Oswestry Disability Index (ODI). ${ }^{20}$ Clinical success was defined as a $\geq 30 \%$ improvement in pain scores ${ }^{21,22}$ and ODI, ${ }^{21,23}$ respectively. Working status, pain medication usage, and patient satisfaction were determined at each follow-up visit. Reoperations and complications were tracked throughout the follow-up period.

\section{Statistical analyses}

Data were analyzed using Predictive Analytics Software (version 18; IBM Corporation, Armonk, NY, USA). Continuous data were reported as the mean \pm standard deviation, and categorical data were reported as frequencies and percentages. Longitudinal changes in back and leg pain severity, as well as ODI score were assessed using repeated measures analysis of variance. McNemar's test was used to analyze changes in employment status before and after treatment. Predictors of solid fusion were determined by univariate logistic regression. Statistical significance was set at $P<0.05$.

\section{Results}

\section{Baseline patient characteristics}

Patients were predominantly middle-age (mean: 41 years; range: $20-58$ years) and female (67\%). Patients typically

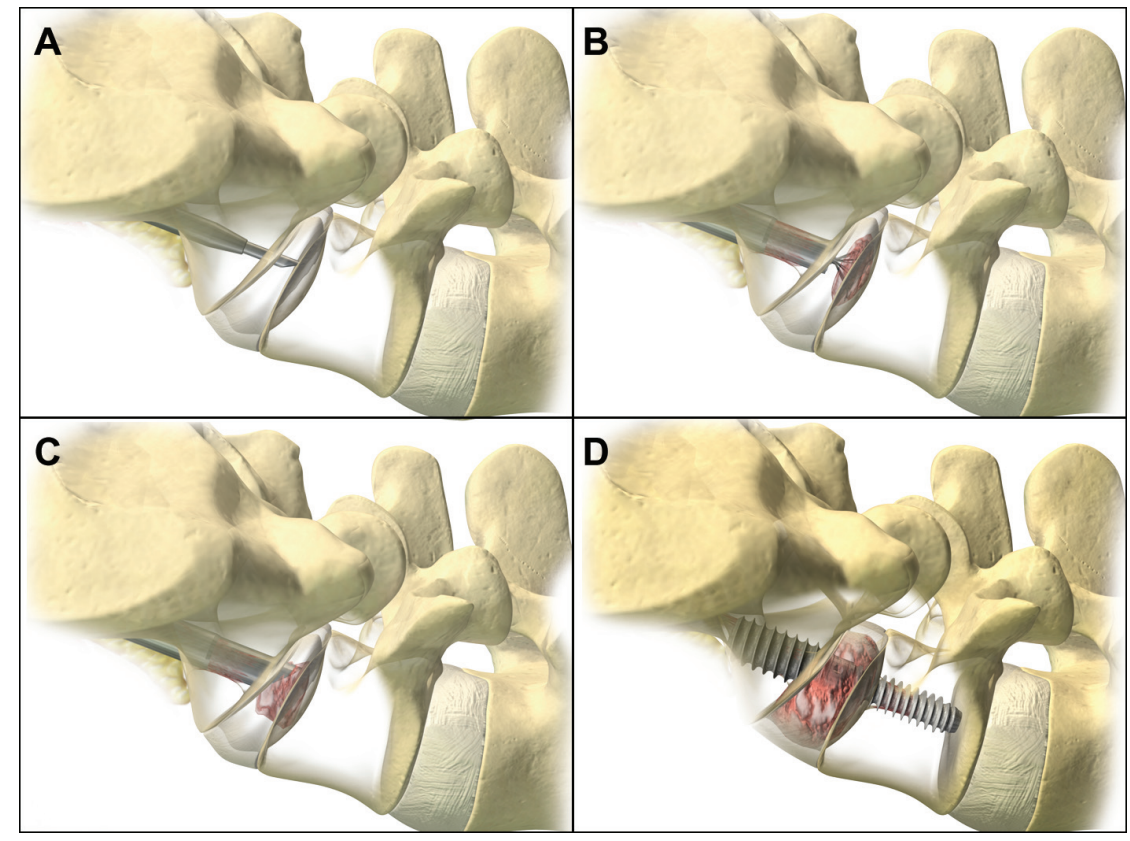

Figure 2 Presacral access with the AxiaLIF system.

Notes: Dilator and guide pin advanced into the L5-SI interspace (A). Radial cutters debulking disc material and preparing the endplates for fusion (B). Insertion of bone graft material in the L5-SI interspace (C). AxiaLIF rod implantation to within 5-10 mm of superior endplate of L5 (D). Images provided courtesy of Baxano Surgical, Inc. ${ }^{32}$ Abbreviation: AxiaLIF, axial lumbar interbody fusion. 
presented with long-standing back pain with a mean severity score of $79 \pm 12$, moderate back dysfunction (ODI $46 \% \pm 16 \%$ ), and a mean index disc height of $52 \% \pm 18 \%$ relative to $\mathrm{L} 4-\mathrm{L} 5$. Leg pain of nonradicular origin was reported in $84 \%$ of patients. Eight $(6.1 \%)$ patients had undergone previous lumbar disc surgery (Table 1).

\section{Procedural details}

The AxiaLIF procedure was successfully completed in all patients. Implant lengths used in this series were $40 \mathrm{~mm}$ $(\mathrm{n}=43), 45 \mathrm{~mm}(\mathrm{n}=55)$, and $50 \mathrm{~mm}(\mathrm{n}=30)$, with the $55 \mathrm{~mm}$ and $60 \mathrm{~mm}$ devices rarely used $(\mathrm{n}=3)$. Posterior facet screw fixation was used in $61(47 \%)$ patients. Mean procedural time was $37 \pm 7$ minutes, blood loss was minimal ( $<100 \mathrm{~mL}$ in all cases), and median hospitalization was 2 days (range: 0 to 14 days).

\section{Pain severity and back function}

Back pain severity decreased $51 \%$ during the follow-up period $(P<0.001)$, from $79 \pm 12$ at the pretreatment visit to $39 \pm 30$ at final follow-up. Leg pain similarly decreased during follow-up, from $45 \pm 30$ to $26 \pm 29$, representing a $42 \%$ average improvement $(P<0.001)$. Clinical success was achieved in $67 \%$ of patients for back pain severity and in $65 \%$ for leg pain severity. ODI scores improved 50\% during follow-up, from $46 \% \pm 16 \%$ to $23 \% \pm 20 \%(P<0.001)$. ODI clinical success was $71 \%$.

Table I Baseline patient characteristics

\begin{tabular}{|c|c|}
\hline Variable & $\begin{array}{l}\text { Values } \\
(n=|3|)\end{array}$ \\
\hline \multicolumn{2}{|l|}{ Demographics } \\
\hline Female sex, n (\%) & $88(67)$ \\
\hline Age, mean $\pm S D$, years & $4 I \pm 8$ \\
\hline Body mass index, mean $\pm \mathrm{SD}, \mathrm{kg} / \mathrm{m}^{2}$ & $26 \pm 4$ \\
\hline \multicolumn{2}{|l|}{ Smoking history, n (\%) } \\
\hline Never & $49(37)$ \\
\hline Former & $40(3 I)$ \\
\hline Current & $42(32)$ \\
\hline \multicolumn{2}{|l|}{ Medical history } \\
\hline Disc height, mean \pm SD & $5.5 \pm 1.8$ \\
\hline Disc height, mean \pm SD, \% relative to L4-L5 & $52 \pm 18$ \\
\hline Back pain duration, mean $\pm S D$, months & $59 \pm 54$ \\
\hline Previous back surgery, n (\%) & $8(6)$ \\
\hline \multicolumn{2}{|l|}{ Symptom severity } \\
\hline Back pain severity, mean $\pm S D$ & $79 \pm 12$ \\
\hline Leg pain severity, mean \pm SD & $45 \pm 30$ \\
\hline Oswestry Disability Index, mean \pm SD & $46 \pm 16$ \\
\hline
\end{tabular}

Abbreviations: $n$, number; SD, standard deviation.

\section{Work status, medication use, and patient satisfaction}

Before treatment with AxiaLIF, 47\% of patients were employed with $24 \%$ working in a full-time capacity. Employment rates at final follow-up were significantly higher $(P<0.001)$, with a $64 \%$ overall employment rate and $44 \%$ of patients employed full-time. Nearly six in ten patients were able to completely discontinue analgesic medications and $18 \%$ reported only occasional (1-3/week) use. Patient satisfaction with the AxiaLIF procedure was excellent, as $83 \%$ of patients reported that they would absolutely or probably have the same surgery again.

\section{Fusion status}

The fusion rate at final follow-up was $87.8 \%(\mathrm{n}=115)$, while $9.2 \%(n=12)$ were graded as indeterminate (no clear signs of bony bridging, but no signs of loosening), and $3.1 \%(n=4)$ showed frank pseudarthrosis. Female sex was a strong predictor of solid fusion (odds ratio: 5.7, 95\% confidence interval: 1.8 to $17.7, P<0.01$ ). Fusion rates were $94 \%$ (83 of 88 ) in females and $74 \%$ (32 of 43 ) in males. No other baseline variable loaded into the logistic regression model at $P<0.10$ (Table 2). A typical example of a solid fusion construct following AxiaLIF is presented in Figure 3.

\section{Complications}

No intraoperative complications, including vascular, neural, urologic, or bowel injuries, were reported. During follow-up, 17 (13.0\%) patients underwent 18 reoperations on the lumbar spine, including pedicle screw fixation $(\mathrm{n}=10)$, total disc replacement of an uninvolved level $(n=3)$, facet screw fixation $(n=3)$, facet screw removal

Table 2 Univariate baseline predictors of solid fusion at final postoperative follow-up

\begin{tabular}{ll}
\hline Variable & $P$-value \\
\hline Sex & $<0.01$ \\
Bone graft type & 0.13 \\
Back pain duration & 0.16 \\
Work status & 0.17 \\
Disc height \% (relative to L4-L5) & 0.20 \\
Back pain severity & 0.21 \\
Body mass index & 0.35 \\
Posterior facet screw fixation & 0.44 \\
Age & 0.53 \\
Smoking history & 0.71 \\
Back function & 0.85 \\
Leg pain severity & 0.91 \\
\hline
\end{tabular}



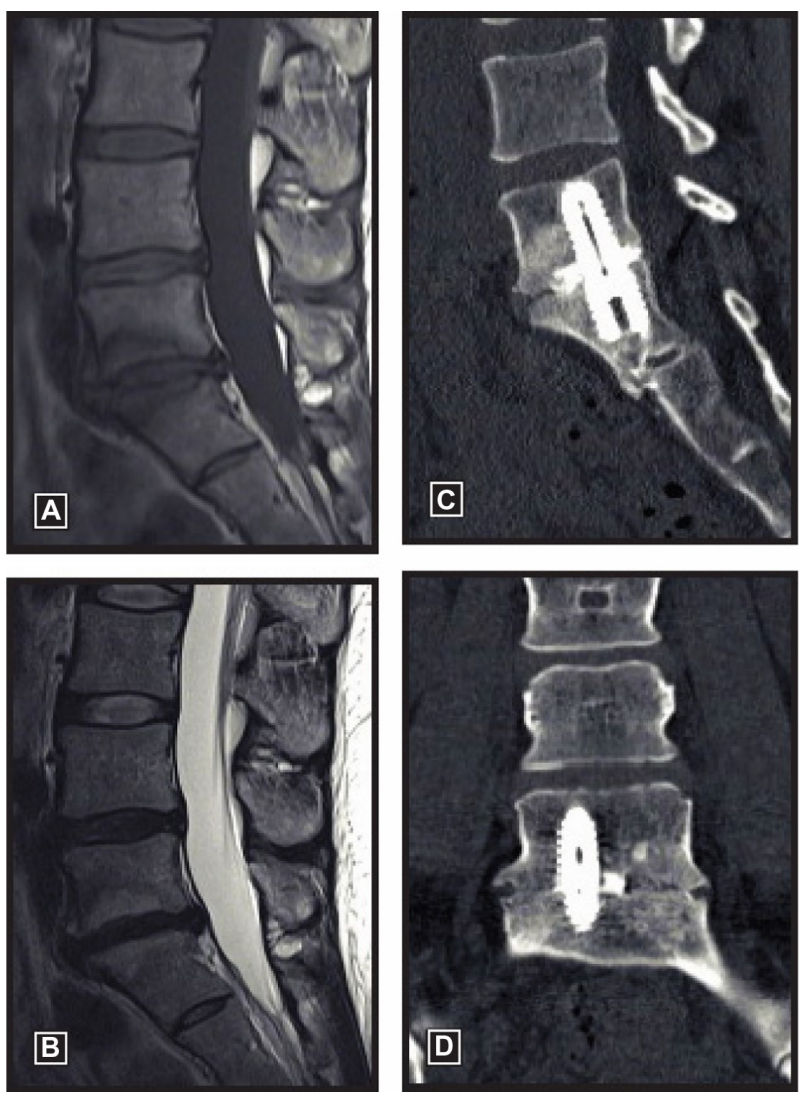

Figure 3 Preoperative TI (A) and T2 (B) images of a 34-year-old woman with a 6-year history of back pain showing discopathy at the L5/SI level with Modic I endplate changes. Postoperative sagittal (C) and coronal (D) CT at I year demonstrates solid fusion. Abbreviation: CT, computed tomography.

$(\mathrm{n}=1)$, and interbody fusion at L4-L5 $(\mathrm{n}=1)$. Eight $(6.1 \%)$ reoperations were at the index level. Broken facet screws were identified in three asymptomatic patients who required no treatment.

\section{Discussion}

This report presents the largest known single-surgeon experience with AxiaLIF and demonstrates that this minimally invasive surgery is a safe and effective means to achieve
L5-S1 fusion in patients with symptomatic DDD. Patient outcomes in the current series are comparable to those reported in other AxiaLIF studies (Table 3). The fusion rate in the current series was $88 \%$. Although others have reported higher fusion rates with AxiaLIF, many of these studies assessed fusion status exclusively with radiographs or with a combination of $\mathrm{CT}$ and radiographs. Discordance in fusion rates assessed with $\mathrm{CT}$ and radiographs is well known, and is illustrated by the study by Bohinski et a ${ }^{15}$ who reported a fusion rate of $100 \%$ with AxiaLIF using postoperative radiographs, but only $88 \%$ using $\mathrm{CT}$. After accounting for differences in imaging modality, the fusion rates reported in our series are comparable to other studies of AxiaLIF.

Although the presacral corridor to the sacrum is generally considered an anatomic safe zone, access through this region can be safely exploited only if the surgeon is intimately familiar with the relevant pelvic anatomy. ${ }^{24}$ The surgeon relies entirely on fluoroscopic guidance since the operative field cannot be directly visualized. Complication risks can be minimized by proper patient selection, use of imaging studies to prospectively identify the proper access trajectory, preoperative bowel preparation techniques, perioperative antibiotic administration, and meticulous operative technique. Bowel perforation is a rare and largely preventable complication with the AxiaLIF. Gundanna et al ${ }^{16}$ reported a $0.6 \%$ bowel injury rate in patients treated with AxiaLIF, with $42 \%$ of these perforations due to frank surgeon error or deviations from recommended procedural steps. In the current series of 131 patients, no bowel perforations were detected. We attribute our success to several strategies that have been adopted during our 6-year experience with the AxiaLIF technology. The anticipated trajectory is predetermined based on a detailed review of imaging studies, with special emphasis on determining the thickness of the perirectal fat pad, locating the interface between the rectum and sacrum, identifying potential aberrant vasculature, and

Table 3 Comparison of studies with axial lumbar interbody fusion for degenerative disc disease

\begin{tabular}{|c|c|c|c|c|c|c|c|c|}
\hline \multirow[t]{2}{*}{ Study } & \multirow[t]{2}{*}{$\mathbf{N}$} & \multirow{2}{*}{$\begin{array}{l}\text { Mean follow-up } \\
\text { (months) }\end{array}$} & \multicolumn{4}{|c|}{ Improvement (\%) } & \multirow{2}{*}{$\frac{\text { Fusion (\%) }}{\text { X-ray }}$} & \multirow[t]{2}{*}{ Other } \\
\hline & & & Back pain & Leg pain & ODI & CT & & \\
\hline Tobler et $\mathrm{al}^{13}$ & 156 & 24 & 63 & - & 54 & - & - & $94 *$ \\
\hline Current series & $13 \mid$ & 21 & 51 & 42 & 50 & 88 & - & - \\
\hline Gerszten et $\mathrm{al}^{14}$ & 99 & 24 & 67 & - & 56 & 94 & - & - \\
\hline Lindley et $\mathrm{al}^{17}$ & 68 & 34 & - & - & - & - & 100 & $91^{* *}$ \\
\hline Bohinski et al ${ }^{15}$ & 50 & 12 & 49 & - & 50 & 88 & 96 & - \\
\hline Patil et al ${ }^{18}$ & 50 & 12 & 56 & - & 52 & - & - & - \\
\hline
\end{tabular}

Notes: Axial lumbar interbody fusion studies with primary diagnosis of degenerative disc disease, $\geq 50$ patients and $\geq I$-year mean follow-up. *Radiograph (57\%), CT (43\%). **imaging modality (CT or X-ray) unclear.

Abbreviations: N, number; ODI, Oswestry Disability Index; CT, computed tomography. 
estimating the probability of achieving proper trajectory. Mechanical bowel cleansing the night before surgery is mandatory since this enhances rectal pliability and reduces sepsis risk in case of a bowel perforation. A Foley catheter may be inserted in the rectum, which helps to delineate the rectum-sacrum interface. Blunt finger dissection taking care to displace the rectum away from the sacrum further reduces risk of bowel puncture.

An analysis of the postmarket surveillance experience in over 9,000 patients treated with AxiaLIF, including over 8,000 L5-S1 cases, reported an overall 1.3\% complication rate. ${ }^{16}$ The AxiaLIF technique spares the posterior musculature, ligaments, and neural elements, as well as major organs and vessels typically encountered during anterior approaches. The advantages of this access route were realized in the current series since no operative complications have been identified over our 6-year experience. Ultimately, $13 \%$ of patients required a reoperation, with $6 \%$ occurring at the index level, over the 21-month mean follow-up period. This reoperation rate compares favorably to a recent metaanalysis that reported a $13 \%$ reoperation rate, including 9\% at the index level, in patients followed for at least 1 year after lumbar fusion surgery for DDD. ${ }^{25}$ Additionally, the lack of intraoperative complications with the AxiaLIF system compares favorably with the typical 10\%-15\% complication rate reported in Food and Drug Administration-regulated trials with open lumbar fusion for DDD. ${ }^{26-31}$ Lastly, serious adverse events such as nerve injury $(0 \%-2.0 \%)$, vascular injury $(1.5 \%-8.8 \%)$, and infection $(0 \%-1.3 \%)$ were reported in these trials, ${ }^{26-31}$ whereas no serious adverse events were reported in the current series.

Our study is limited by the retrospective nature of the analysis. Additionally, all patients underwent fusion at L5-S1 and, therefore, no conclusions can be drawn regarding the effectiveness or safety of two-level AxiaLIF from this report. Lastly, mean patient follow-up was 21 months. Although this represents one of the longest follow-up reports following AxiaLIF surgery, long-term clinical and radiographic outcomes are unknown. However, it is reasonable to assume that the clinical course of a patient with an accomplished fusion will not be different than after fusions obtained by other techniques.

Overall, single-level AxiaLIF is a safe and effective means to achieve lumbosacral fusion in patients with symptomatic DDD.

\section{Acknowledgment}

The authors thank Mr Randy Asher for graphical assistance.

\section{Disclosure}

DJZ, LEM, and JEB are consultants to TranS1, Inc. The authors report no other conflicts of interest in this work.

\section{References}

1. Niu G, Yang J, Wang R, Dang S, Wu EX, Guo Y. MR imaging assessment of lumbar intervertebral disk degeneration and age-related changes: apparent diffusion coefficient versus T2 quantitation. AJNR Am J Neuroradiol. 2011;32(9):1617-1623.

2. Hicks GE, Morone N, Weiner DK. Degenerative lumbar disc and facet disease in older adults: prevalence and clinical correlates. Spine (Phila Pa 1976). 2009;34(12):1301-1306.

3. DePalma MJ, Ketchum JM, Saullo T. What is the source of chronic low back pain and does age play a role? Pain Med. 2011;12(2): 224-233.

4. Chou R, Atlas SJ, Stanos SP, Rosenquist RW. Nonsurgical interventional therapies for low back pain: a review of the evidence for an American Pain Society clinical practice guideline. Spine (Phila Pa 1976). 2009;34(10):1078-1093.

5. Carey TS, Garrett JM, Jackman AM. Beyond the good prognosis. Examination of an inception cohort of patients with chronic low back pain. Spine (Phila Pa 1976). 2002;25(1):115-120.

6. Von Korff M. Studying the natural history of back pain. Spine Spine (Phila Pa 1976). 1994;19(Suppl 18):2041S-2046S.

7. Smith SE, Darden BV, Rhyne AL, Wood KE. Outcome of unoperated discogram-positive low back pain. Spine (Phila Pa 1976). 1995;20(18): 1997-2000; discussion 2000-2001.

8. Mobbs RJ, Sivabalan P, Li J. Minimally invasive surgery compared to open spinal fusion for the treatment of degenerative lumbar spine pathologies. J Clin Neurosci. 2012;19(6):829-835.

9. Payer M. "Minimally invasive" lumbar spine surgery: a critical review. Acta Neurochir (Wien). 2011;153(7):1455-1459.

10. Cragg A, Carl A, Casteneda F, Dickman C, Guterman L, Oliveira C. New percutaneous access method for minimally invasive anterior lumbosacral surgery. J Spinal Disord Tech. 2004;17(1):21-28.

11. Stippler M, Turka M, Gerszten PC. Outcomes after percutaneous TranS1 AxiaLIF ${ }^{\circledR}$ L5-S1 interbody fusion for intractable lower back pain. The Internet Journal of Spine Surgery. 2009;5(1):1-12.

12. Tobler WD, Ferrara LA. The presacral retroperitoneal approach for axial lumbar interbody fusion: a prospective study of clinical outcomes, complications and fusion rates at a follow-up of two years in 26 patients. J Bone Joint Surg Br. 2011;93(7):955-960.

13. Tobler WD, Gerszten PC, Bradley WD, Raley TJ, Nasca RJ, Block JE. Minimally invasive axial presacral L5-S1 interbody fusion: twoyear clinical and radiographic outcomes. Spine (Phila Pa 1976). 2011;36(20):E1296-E1301.

14. Gerszten PC, Tobler WD, Nasca RJ. Retrospective analysis of L5-S1 axial lumbar interbody fusion (AxiaLIF): a comparison with and without the use of recombinant human bone morphogenetic protein-2. Spine J. 2011;11(11):1027-1032.

15. Bohinski RJ, Jain VV, Tobler WD. Presacral retroperitoneal approach to axial lumbar interbody fusion: a new, minimally invasive technique at L5-S1: clinical outcomes, complications, and fusion rates in 50 patients at 1-year follow-up. SAS J. 2010;4(2):54-62.

16. Gundanna MI, Miller LE, Block JE. Complications with axial presacral lumbar interbody fusion: a 5-year postmarketing surveillance experience. SAS J. 2011;5(3):90-94.

17. Lindley EM, McCullough MA, Burger EL, Brown CW, Patel VV. Complications of axial lumbar interbody fusion. J Neurosurg Spine. 2011;15(3):273-279.

18. Patil SS, Lindley EM, Patel VV, Burger EL. Clinical and radiological outcomes of axial lumbar interbody fusion. Orthopedics. 2010;33(12):883. 
19. Marotta N, Cosar M, Pimenta L, Khoo LT. A novel minimally invasive presacral approach and instrumentation technique for anterior L5-S1 intervertebral discectomy and fusion: technical description and case presentations. Neurosurg Focus. 2006;20(1):E9.

20. Fairbank JC, Pynsent PB. The Oswestry Disability Index. Spine (Phila Pa 1976). 2000;25(22):2940-2952; discussion 2952.

21. Ostelo RW, Deyo RA, Stratford P, et al. Interpreting change scores for pain and functional status in low back pain: towards international consensus regarding minimal important change. Spine (Phila Pa 1976). 2008;33(1):90-94.

22. Hägg O, Fritzell P, Nordwall A; Swedish Lumbar Spine Study Group. The clinical importance of changes in outcome scores after treatment for chronic low back pain. Eur Spine J. 2003;12(1):12-20.

23. Zigler J, Delamarter R, Spivak JM, et al. Results of the prospective, randomized, multicenter Food and Drug Administration investigational device exemption study of the ProDisc-L total disc replacement versus circumferential fusion for the treatment of 1-level degenerative disc disease. Spine. 2007;32(11):1155-1162; discussion 1163.

24. Yuan PS, Day TF, Albert TJ, et al. Anatomy of the percutaneous presacral space for a novel fusion technique. J Spinal Disord Tech. 2006;19(4):237-241.

25. Phillips FM, Slosar PJ, Youssef JA, Andersson G, Papatheofanis F. Lumbar spine fusion for chronic low back pain due to degenerative disc disease: a systematic review. Spine (Phila Pa 1976). 2013;38(7): E409-E422.
26. US Food and Drug Administration. Summary of Safety and Effectiveness: BAK Interbody Fusion System with Instrumentation. Rockville, MD: Food and Drug Administration; 1996. Available from: http://www.accessdata. fda.gov/cdrh_docs/pdf/p950002.pdf. Accessed June 3, 2013.

27. US Food and Drug Administration. Summary of Safety and Effectiveness: Ray Threaded Fusion Cage (TFC) with Instrumentation. Rockville, MD: Food and Drug Administration; 1996. http://www.accessdata.fda.gov/ cdrh_docs/pdf/P950019a.pdf. Accessed June 3, 2013.

28. US Food and Drug Administration. Summary of Safety and Effectiveness: INTER FIX Threaded Fusion Device. Rockville, MD: Food and Drug Administration; 1999. http://www.accessdata.fda.gov/ cdrh_docs/pdf/P970015b.pdf. Accessed June 3, 2013.

29. US Food and Drug Administration. Summary of Safety and Effectiveness: InFUSE Bone Graft/LT-CAGE Lumbar Tapered Fusion Device. Rockville, MD: Food and Drug Administration; 2002. http://www.accessdata. fda.gov/cdrh_docs/pdf/P000058b.pdf. Accessed June 3, 2013.

30. US Food and Drug Administration. Summary of Safety and Effectiveness: PRODISC-L Total Disc Replacement. Rockville, MD: Food and Drug Administration; 2006. http://www.accessdata.fda.gov/ cdrh_docs/pdf5/P050010b.pdf. Accessed June 3, 2013.

31. US Food and Drug Administration. Summary of Safety and Effectiveness: CHARITE Artificial Disc. Rockville, MD: Food and Drug Administration; 2004. http://www.accessdata.fda.gov/cdrh_docs/ pdf4/P040006b.pdf. Accessed June 3, 2013

32. AxiaLIF [patient literature]. Raleigh, NC: Baxano Surgical, Inc; 2013.
Clinical Interventions in Aging

\section{Publish your work in this journal}

Clinical Interventions in Aging is an international, peer-reviewed journal focusing on evidence-based reports on the value or lack thereof of treatments intended to prevent or delay the onset of maladaptive correlates of aging in human beings. This journal is indexed on PubMed Central, MedLine, the American Chemical Society's 'Chemical Abstracts Ser-

\section{Dovepress}

vice' (CAS), Scopus and the Elsevier Bibliographic databases. The manuscript management system is completely online and includes a very quick and fair peer-review system, which is all easy to use. Visit http://www.dovepress.com/testimonials.php to read real quotes from published authors. 